\title{
I CONGRÉS D'HISTORIA D'ALCANAR. 750 ANIVERSARI DE LA CARTA POBLA (1239-1989)
}

\author{
Por \\ LUIS FERNANDO BERNABÉ PONS
}

Se celebró durante los días 24, 25 y 26 de febrero de 1989, en el marco de la conmemoración de su Carta Puebla, el Primer Congreso de Historia de Alcanar (Tarragona). Se presentaron numerosas comunicaciones en torno a diversos temas, articuladas airededor de unas ponencias principales. La primera de ellas (que inauguraba a su vez el Congreso) fue llevada a cabo por el Dr. Josep M. ${ }^{a}$ Font i Rius, profesor emérito de la Universidad de Barcelona, y versó sobre la historia medieval de la zona del Montsià. Al día siguiente, el Dr. Josep Trenchs Odena, Catedrático de la Universidad de Valencia, y la Dra. M. a José Carbonell Boria se centraron sobre la Carta Puebla con su ponencia: «Una data histórica: Alcanar 1239». El mismo día por la tarde, tuvo lugar la ponencia del Dr. Míkel de Epalza, Catedrático de la Universidad de Alicante, y Luis F. Bernabé Pons, sobre «Alcanar a època àrab. 500 anys de presència islàmica», en la que se reflexionaba sobre la historia árabe de toda la zona de la que Alcanar forma parte integrante.

Seguido por un numeroso público, el congreso desarrolló con éxito todas las ponencias y comunicaciones previstas, que abarcaban una amplísima gama de materias en torno a las condiciones históricas, geográficas y sociales de Alcanar. 